\title{
L. Rosenthall
}

\section{A crossover comparison of four peripheral bone-site measurements to identify central osteopenia and osteoporosis in women}

Accepted: 15 May 2002 / Published online: 18 July 2002

(C) Springer-Verlag 2002

\begin{abstract}
The objective of this study was to assess the ability of four peripheral bone measurement sites to predict low bone mineral density of the lumbar spine, femoral neck, and total hip as defined by the WHO classification, and to evaluate their role as a screening procedure for central dual-energy X-ray absorptiometry (DXA). One thousand three hundred white women patients aged $58.3 \pm 13.9$ years were enrolled. Correlations between the peripheral and central sites were moderate, varying between 0.51 and 0.67 . In receiver-operating characteristic (ROC) analysis, the areas under the curve for the peripheral sites revealed a few small, but significant, differences between sites. The optimal cut-point was derived from the ROC data for each site to assess its value as a screening parameter. These proved to be unsatisfactory, because the average number of false positives and false negatives were $18 \%$ and $24 \%$, respectively. A proposal is made which entails two cut-points, one for an acceptable percentage of false negatives and the other for an acceptable number of false positives. Patients with t-scores between these cut-points would be referred for central DXA for classification. The result is a substantial decrease in the number of false negatives, i.e., patients who would be candidates for treatment. The contentious issue is what proportion of supplemental DXAs is considered logistically and economically acceptable for any of the peripheral site measurements to be useful.
\end{abstract}

Résumé L'objectif de cette étude était d'apprécier la capacité de quatre sites osseux périphériques de mesure à prédire la basse densité minérale de la colonne vertébrale lombaire, du col fémoral et de la hanche comme défini par la classification de OMS, et évaluer leur rôle comme procédure de sélection pour l'examen d'absorptiométrie biphotonique central (DXA). 1300 patientes de race blanche âgées de 58.3 \pm 13.9 années ont été enrôlées. Les

\footnotetext{
L. Rosenthall (

McGill University Health Center, The Montreal General Hospital, 1650 Cedar Ave., Montreal, Canada H3G 1A4 e-mail: rosenthl@rad.mgh.mcgill.ca

Tel.: +1-514-9341934
}

corrélations entre les emplacements périphériques et centraux étaient modérées, variant entre 0.51 et 0.67. Dans l'analyse de Caractéristique de l'Opérateur (ROC), les régions sous la courbe pour les emplacements périphériques ont révélé quelques faibles mais significatives différences entre les emplacements. Le point d'intersection optimal a été déduit des données du ROC pour chaque site pour préciser sa valeur comme paramètre de la sélection. Ceci s'est révélé peu satisfaisant parce que le nombre moyen de faux positifs et de faux négatifs étaient de $18 \%$ et $24 \%$, respectivement. Une proposition est faite de considérer deux points d'intersection, un pour un pourcentage acceptable de faux négatifs et l'autres pour un nombre acceptable de faux positifs. Les malades avec un t-score entre ces points relèveraient d'un examen DXA central pour classification. Le résultat est une baisse substantielle du nombre de faux négatifs, c'est-à-dire du nombre de malades qui seraient des candidats pour un traitement. La question qui demeure est : quelle proportion de DXA supplémentaire peut être considérée sur le plan logistique et économique comme acceptable pour qu'un site periphérique de mesure soit utile.

\section{Introduction}

There are many peripheral bone density measuring devices available commercially. They have the attributes of portability, relatively low cost, and the potential for mass screening of menopausal women and others at risk for fracture, particularly in remote areas where there is no convenient access to central bone measurements by the present gold standard - dual-energy X-ray absorptiometry (DXA). The crossover study reported here was designed to evaluate the efficacy of four peripheral bone measurement sites to predict low central bone mineral density (BMD) as defined by the WHO classification and to evaluate their potential as a screening procedure for central DXA $[2,16]$. 
Table 1 T-score correlations (95\% CIL) between measurement sites, $n=1300$

\begin{tabular}{|c|c|c|c|c|c|}
\hline & Lumbar spine & Femoral neck & $\begin{array}{l}\text { Minimum of } \\
\text { lumbar spine } \\
\text { and femoral neck }\end{array}$ & Total hip & $\begin{array}{l}\text { Minimum of } \\
\text { lumbar spine } \\
\text { and total hip }\end{array}$ \\
\hline Lumbar spine & & $0.63(0.59,0.66)$ & & $0.65(0.61,0.68)$ & \\
\hline Distal forearm & $0.60(0.56,0.63)$ & $0.65(0.62,0.68)$ & $0.66(0.63,0.69)$ & $0.67(0.63,0.69)$ & $0.67(0.64,0.70)$ \\
\hline Proximal Forearm & $0.57(0.53,0.60)$ & $0.60(0.56,0.63)$ & $0.62(0.59,0.65)$ & $0.59(0.56,0.63)$ & $0.63(0.59,0.66)$ \\
\hline Finger & $0.56(0.52,0.59)$ & $0.56(0.52,0.60)$ & $0.57(0.53,0.61)$ & $0.55(0.51,0.58)$ & $0.59(0.55,0.62)$ \\
\hline US calcaneal Stiffness & $0.51(0.47,0.55)$ & $0.57(0.54,0.61)$ & $0.59(0.55,0.62)$ & $0.59(0.55,0.62)$ & $0.59(0.54,0.62)$ \\
\hline
\end{tabular}

\section{Methods}

One thousand three hundred white women aged 58.3 \pm 13.9 (range 20-91) years who were referred for central BMD measurements of the lumbar spine, femoral neck, and total hip by DXA (GE-LUNAR, Madison, WI, USA) agreed to the peripheral measurements. These consisted of calcaneal ultrasonometry (Achilles Plus, GE-LUNAR, Madison, WI, USA), quantitative radiographic absorptiometry of the third finger (accuDEXA, Schick, New York, NY, USA), and DXA of the distal and one third proximal radius+ulna in the nondominant forearm (pDEXA, Norland, Fort Atkinson, WI, USA). Only patients who were ambulatory without support, free of injury or orthopaedic hardware in the regions of interest, and who had the required measurement of all peripheral sites were included in the final analysis. No other restrictions were imposed.

The t-scores for the lumbar spine and femoral neck were calculated from the young female adult peak bone density value reported in the Canadian Multicenter Osteoporosis Study after the GE-LUNAR BMDs were converted to Hologic BMDs using crosscalibration equations $[3,13]$. Total hip t-scores were derived from the NHANES III normative data base for young female adults after conversion to a Hologic base utilizing the relationship $\mathrm{BMD}_{\text {Hologic }}=$ $0.948 \times \mathrm{BMD}_{\mathrm{LUNAR}}-0.014$ (personal communication from GELUNAR). T-scores for the peripheral site measurements were derived from the databases provided by the manufacturer, because there is no standardized normative database for the various devices.

A patient was classified as osteoporotic if either the lumbar spine, femoral neck, or both had $\mathrm{t}$-scores $\leq-2.5$. If the lowest $\mathrm{t}$ score of the two central sites was $<-1$, the patient was identified as osteopenic, osteoporotic, or both, for purposes of analysis. The same classification was used in the combination of lumbar spine and total hip. In this study cohort, the prevalence of osteoporosis (minimum t-score $\leq-2.5$ ); and osteopenia, osteoporosis, or both (minimum $\mathrm{t}$-score $<-1$ ), was $26.5 \%$ and $83.9 \%$, respectively, for the lumbar spine/femoral neck category, and $19.7 \%$ and $73.0 \%$, respectively, for the lumbar/total hip category. The finger and forearm of the nondominant side were measured, but the calcaneal stiffness was derived from the mean of the right and left heels. Stiffness is a GE-LUNAR propriety parameter combining the speed of sound (SOS) and broadband ultrasound attenuation (BUA) by the expression 0.68(BUA)+0.28(SOS)-420.

Short-term precision error for the peripheral devices was determined on the first 200 patients by paired measurements, with repositioning between scans. The coefficients of variation were $2.82 \%$ (mean $\mathrm{BMD}=0.279 \pm 0.05 \mathrm{~g} / \mathrm{cm}^{2}$ ) distal forearm, $1.75 \%$ (mean $\left.\mathrm{BMD}=0.638 \pm 0.12 \mathrm{~g} / \mathrm{cm}^{2}\right)$ proximal forearm, $1.71 \%$ (mean $=0.456 \pm$ $0.08 \mathrm{~g} / \mathrm{cm}^{2}$ ) finger, and $2.15 \%$ (mean $=82.3 \pm 14.8$ ) calcaneal stiffness.

Analyses were performed with the NCSS 2001 statistical package (NCSS, Kaysville, UT, USA) to obtain site-matched correlations, multiple linear regressions, and receiver-operating characteristic (ROC) curves.

\section{Results}

By regressing the minimum $\mathrm{t}$-score of either the lumbar spine or femoral neck on the two forearm t-scores, an ad-
Table 2 Receiver-operating characteristic (ROC) analysis for lumbar spine or femoral neck osteoporosis ( $\mathrm{t}$-score $\leq-2.5$ ), $n=1300$

\begin{tabular}{llll}
\hline Site & Area & SE & $95 \%$ CIL \\
\hline Distal forearm & 0.827 & 0.014 & $0.80,0.86$ \\
Proximal forearm & 0.815 & 0.015 & $0.79,0.84$ \\
Finger & 0.775 & 0.015 & $0.74,0.81$ \\
US Calcaneus SOS & 0.800 & 0.015 & $0.77,0.83$ \\
Combined forearm index* & 0.841 & 0.014 & $0.81,0.87$ \\
\hline
\end{tabular}

*Combined t-score $=0.364\left(\mathrm{D}_{\mathrm{t}}\right)+0.145\left(\mathrm{P}_{\mathrm{t}}\right)-0.939$

ditional parameter - the combined forearm index - was derived in order to determine its efficacy. Thus, predicted minimum $\mathrm{t}$-score was (combined forearm index) $=$ $0.364 \mathrm{D}_{\mathrm{t}}+0.145 \mathrm{P}_{\mathrm{t}}-0.939$, where $\mathrm{D}_{\mathrm{t}}$ and $\mathrm{P}_{\mathrm{t}}$ denote the distal and proximal forearm t-scores, respectively. Similarly, for lumbar spine and total hip, predicted minimum $\mathrm{t}$-score was $($ combined forearm index $)=0.437 \mathrm{D}_{\mathrm{t}}+0.1530_{0}$ -0.514 .

Table 1 details the site-matched correlations and their 95\% confidence limits. There was only a moderate, but significant, correlation between the peripheral and central sites, which varied from 0.51 to 0.67 . The correlation between distal forearm and lumbar spine was significantly greater than that of the calcaneal stiffness and lumbar spine. For the femoral neck, total hip, minimum t-score of either the lumbar spine and femoral neck, and minimum t-score of either the lumbar spine and total hip, the correlations with the distal forearm were significantly greater than those obtained with calcaneal stiffness, proximal forearm, and finger measurements.

The results of ROC analysis of lumbar spine or femoral neck osteoporosis is given in Table 2. Areas under the curve (AUC) varied from 0.775 for the finger to a high of 0.841 for the combined forearm index. The AUCs of the distal forearm alone and combined forearm index were significantly greater than the finger by $6.7 \%$ and $8.5 \%$, respectively, whereas other paired comparisons showed no difference. In the ROC analysis of lumbar spine or total hip osteoporosis, AUC of the combined forearm index was significantly greater than that of the finger by $7.6 \%$, but no difference was observed between the other comparisons. AUCs for lumbar spine, or femoral neck osteopenia or osteoporosis, or both, (t-score $<-1)$ varied from 0.805 for stiffness to 0.876 for the combined forearm index (Table 3 ). There was no significant improvement in the AUC of the combined forearm 
Table 3 Receiver-operating characteristic (ROC) analysis for lumbar spine or femoral neck osteopenia, osteoporosis, or both category (t-score $<-1), n=1300$

\begin{tabular}{llll}
\hline Site & Area & SE & $95 \%$ CIL \\
\hline Distal forearm & 0.854 & 0.011 & $0.83,0.88$ \\
Proximal forearm & 0.850 & 0.011 & $0.83,0.87$ \\
Finger & 0.827 & 0.013 & $0.80,0.85$ \\
US Calcaneus SOS & 0.805 & 0.014 & $0.78,0.83$ \\
Combined distal & 0.876 & 0.010 & $0.86,0.90$ \\
and proximal forearm* & & &
\end{tabular}

*Combined t-score $=0.364\left(\mathrm{D}_{\mathrm{t}}\right)+0.145\left(\mathrm{P}_{\mathrm{t}}\right)-0.935$

index over the distal and proximal forearm alone, but it was significantly greater than the finger and stiffness by $5.9 \%$ and $8.8 \%$, respectively. Distal forearm exceeded stiffness by a significant $6 \%$. For the lumbar spine, or total hip osteopenia or osteoporosis, or both (t-score $<-1)$, the combined forearm index was significantly greater than those of the finger and calcaneal stiffness by $5.4 \%$ and $7.7 \%$, respectively, but not the distal forearm alone. The AUC of the distal forearm exceeded the stiffness by a significant $6.5 \%$

The optimal cut point, i.e., the t-score for which the sum of the sensitivity and specificity is a maximum, was obtained from the ROC output for each of the sites. The sensitivity varied from 0.76 to 0.80 , specificity from 0.71 to 0.80 , and accuracy from 0.68 to 0.75 for osteoporosis (Table 4). Corresponding positive predictive values varied from 0.43 to 0.50 , whereas the negative predictive values varied from 0.88 to 0.91 for an osteoporosis prevalence of $26.5 \%$. For either osteopenia, osteoporosis, or both (t-score $<-1$ ), the sensitivity, specificity, and accuracy varied from 0.62 to $0.82,0.76$ to 0.88 , and 0.66 to
0.81 , respectively (Table 5). Corresponding positive and negative predictive values varied from 0.94 to 0.96 and 0.31 to 0.45 , respectively, for a prevalence of $83.9 \%$. The kappa scores varied from 0.33 to 0.45 for the optimal osteoporotic cut-points, and from 0.28 to 0.46 for optimal osteopenic cut-points (Tables 4 and 5). On a scale of $0-1$, kappa scores between 0.40 and 0.75 indicate moderate agreement beyond chance alone, and less than 0.40 signifies poor agreement with the central results.

\section{Discussion}

The prime purpose of this study was to evaluate peripheral bone mineral measurements as a screening mechanism for the central DXA measurements of lumbar spine and upper femur, arguably the present gold standard for assessing osteoporosis and fracture risk. The population of women studied in this analysis included those who were screened in their pre-, peri- and postmenopausal years for investigation of bone pain with and without fractures, amenorrhea, medications known to induce mineral depletion, and other less frequent conditions. This is comparable to the spectrum of indications expected in patients who would be screened with peripheral measuring devices because of the lack of ready accessibility to DXA for direct-site measurement of the lumbar spine and proximal femur. The latter site is particularly important to assess because of the high morbidity associated with hip fractures in the elder population. In order to minimize selectivity, the only exclusions from our population were related to technical and anatomical restrictions and the failure to complete the measurements at all sites satisfactorily.

Table 4 Lumbar spine or femoral neck osteoporosis (t-score $\leq-2.5$ ). Prevalence $26.5 \%, n=1300$. Cut-point Cut-point for maximum $\sum$ (sensitivity+specificity), $P P V$ positive predictive value, $N P V$ negative predictive value, $D X A$ dual-energy X-ray absorptiometry

\begin{tabular}{llllllll}
\hline Site & Cut-point & Sensitivity & Specificity & PPV & NVP & $\begin{array}{c}\text { Accuracy } \\
\text { (kappa) }\end{array}$ & $\begin{array}{c}\% \text { DXA } \\
\text { supplement }\end{array}$ \\
\hline Distal forearm & -1.68 & 0.80 & 0.71 & 0.50 & 0.91 & $0.73(0.43)$ & 43 \\
Proximal forearm & -3.27 & 0.78 & 0.72 & 0.49 & 0.90 & $0.73(0.41)$ & 41 \\
Finger & -1.32 & 0.76 & 0.76 & 0.43 & 0.88 & $0.68(0.33)$ & 46 \\
US calcaneal stiffness & -1.26 & 0.79 & 0.79 & 0.45 & 0.90 & $0.69(0.36)$ & 46 \\
Combined forearm index* & -2.05 & 0.80 & 0.80 & 0.51 & 0.91 & $0.75(0.45)$ & 41 \\
\hline
\end{tabular}

$*$ Combined t-score $=0.364\left(\mathrm{D}_{\mathrm{t}}\right)+0.145\left(\mathrm{P}_{\mathrm{t}}\right)-0.939$

Table 5 Lumbar spine or femoral neck osteopenia and/or osteoporosis (t-score <-1). Prevalence 83.9\%, $n=1300$. Cut-point Cut-point for maximum $\sum$ (sensitivity+specificity), $P P V$ positive predictive value, $N P V$ negative predictive value, $D X A$ dual-energy X-ray absorptiometry

\begin{tabular}{llllllll}
\hline Site & Cut-point & Sensitivity & Specificity & PPV & NVP & $\begin{array}{c}\text { Accuracy } \\
\text { (kappa) }\end{array}$ & $\begin{array}{c}\% \text { DXA } \\
\text { supplement }\end{array}$ \\
\hline Distal forearm & -0.82 & 0.80 & 0.77 & 0.95 & 0.42 & $0.80(0.43)$ & 71 \\
Proximal forearm & -1.74 & 0.79 & 0.77 & 0.95 & 0.42 & $0.79(0.42)$ & 70 \\
Finger & -1.01 & 0.62 & 0.88 & 0.96 & 0.31 & $0.66(0.28)$ & 58 \\
US calcaneal stiffness & -0.85 & 0.71 & 0.76 & 0.94 & 0.34 & $0.73(0.32)$ & 64 \\
Combined forearm index* & -1.47 & 0.82 & 0.78 & 0.95 & 0.45 & $0.81(0.46)$ & 72 \\
\hline
\end{tabular}

*Combined t-score $=0.364\left(\mathrm{D}_{\mathrm{t}}\right)+0.145\left(\mathrm{P}_{\mathrm{t}}\right)-0.939$ 
Table 6 Lumbar spine or femoral neck osteoporosis ( $\mathrm{t}$-score $\leq-2.5), n=1300$. FN false negative, $F P$ false positive, $D X A$ dual-energy X-ray absorptiometry

Table 7 Lumbar spine or fem-
oral neck osteopenia and/or os-
teoporosis $(\mathrm{t}-$-score $<-1)$,
$n=1300$. FN false negative,
FP false positive, $D X A$ dual-
energy X-ray absorptiometry

$*$ Combined t-score $=0.364\left(\mathrm{D}_{\mathrm{t}}\right)$ $+0.145\left(\mathrm{P}_{\mathrm{t}}\right)-0.939$

\begin{tabular}{|c|c|c|c|}
\hline Site & Range (\%) & Cut-points & $\begin{array}{l}\% \text { Central DXA } \\
\text { supplement }\end{array}$ \\
\hline Distal forearm & $\begin{array}{l}5 \mathrm{FN} \text { to } 5 \mathrm{FP} \\
10 \mathrm{FN} \text { to } 10 \mathrm{FP} \\
15 \mathrm{FN} \text { to } 15 \mathrm{FP}\end{array}$ & $\begin{array}{l}-0.93 \text { to }-2.82 \\
-1.32 \text { to }-2.42 \\
-1.51 \text { to }-2.22\end{array}$ & $\begin{array}{l}55 \\
34 \\
22\end{array}$ \\
\hline Proximal forearm & $\begin{array}{l}5 \mathrm{FN} \text { to } 5 \mathrm{FP} \\
10 \mathrm{FN} \text { to } 10 \mathrm{FP} \\
15 \mathrm{FN} \text { to } 15 \mathrm{FP}\end{array}$ & $\begin{array}{l}-1.85 \text { to }-5.17 \\
-2.32 \text { to }-4.55 \\
-2.82 \text { to }-4.16\end{array}$ & $\begin{array}{l}56 \\
39 \\
24\end{array}$ \\
\hline Finger & $\begin{array}{l}5 \mathrm{FN} \text { to } 5 \mathrm{FP} \\
10 \mathrm{FN} \text { to } 10 \mathrm{FP} \\
15 \mathrm{FN} \text { to } 15 \mathrm{FP}\end{array}$ & $\begin{array}{l}-0.01 \text { to }-3.09 \\
-0.52 \text { to }-2.45 \\
-0.92 \text { to }-2.10\end{array}$ & $\begin{array}{l}67 \\
47 \\
31\end{array}$ \\
\hline US calcaneal stiffness & $\begin{array}{l}5 \mathrm{FN} \text { to } 5 \mathrm{FP} \\
10 \mathrm{FN} \text { to } 10 \mathrm{FP} \\
15 \mathrm{FN} \text { to } 15 \mathrm{FP}\end{array}$ & $\begin{array}{l}-0.59 \text { to }-2.18 \\
-0.95 \text { to }-1.89 \\
-1.11 \text { to }-1.72\end{array}$ & $\begin{array}{l}62 \\
40 \\
28\end{array}$ \\
\hline Combined forearm index* & $\begin{array}{l}5 \mathrm{FN} \text { to } 5 \mathrm{FP} \\
10 \mathrm{FN} \text { to } 10 \mathrm{FP} \\
15 \mathrm{FN} \text { to } 15 \mathrm{FP}\end{array}$ & $\begin{array}{l}-1.62 \text { to }-2.66 \\
-1.77 \text { to }-2.44 \\
-1.90 \text { to }-2.28\end{array}$ & $\begin{array}{l}52 \\
36 \\
20\end{array}$ \\
\hline
\end{tabular}

\begin{tabular}{|c|c|c|c|}
\hline Site & Range (\%) & Cut-points & $\begin{array}{l}\% \text { Central DXA } \\
\text { supplement }\end{array}$ \\
\hline Distal forearm & $\begin{array}{l}5 \mathrm{FN} \text { to } 5 \mathrm{FP} \\
10 \mathrm{FN} \text { to } 10 \mathrm{FP} \\
15 \mathrm{FN} \text { to } 15 \mathrm{FP}\end{array}$ & $\begin{array}{r}0.05 \text { to }-1.66 \\
-0.33 \text { to }-1.35 \\
-0.64 \text { to }-1.12\end{array}$ & $\begin{array}{l}46 \\
28 \\
15\end{array}$ \\
\hline Proximal forearm & $\begin{array}{l}5 \mathrm{FN} \text { to } 5 \mathrm{FP} \\
10 \mathrm{FN} \text { to } 10 \mathrm{FP} \\
15 \mathrm{FN} \text { to } 15 \mathrm{FP}\end{array}$ & $\begin{array}{l}-0.55 \text { to }-2.92 \\
-0.99 \text { to }-2.60 \\
-1.31 \text { to }-2.31\end{array}$ & $\begin{array}{l}43 \\
29 \\
19\end{array}$ \\
\hline Finger & $\begin{array}{l}5 \mathrm{FN} \text { to } 5 \mathrm{FP} \\
10 \mathrm{FN} \text { to } 10 \mathrm{FP} \\
15 \mathrm{FN} \text { to } 15 \mathrm{FP}\end{array}$ & $\begin{array}{l}0.90 \text { to }-1.59 \\
0.39 \text { to }-1.15 \\
0.00 \text { to }-0.95\end{array}$ & $\begin{array}{l}51 \\
32 \\
22\end{array}$ \\
\hline US calcaneal stiffness & $\begin{array}{l}5 \mathrm{FN} \text { to } 5 \mathrm{FP} \\
10 \mathrm{FN} \text { to } 10 \mathrm{FP} \\
15 \mathrm{FN} \text { to } 15 \mathrm{FP}\end{array}$ & $\begin{array}{r}0.06 \text { to }-1.54 \\
-0.21 \text { to }-1.20 \\
-0.43 \text { to }-1.11\end{array}$ & $\begin{array}{l}57 \\
36 \\
26\end{array}$ \\
\hline Combined forearm index $*$ & $\begin{array}{l}5 \mathrm{FN} \text { to } 5 \mathrm{FP} \\
10 \mathrm{FN} \text { to } 10 \mathrm{FP} \\
15 \mathrm{FN} \text { to } 15 \mathrm{FP}\end{array}$ & $\begin{array}{l}-1.08 \text { to }-1.91 \\
-1.27 \text { to }-1.73 \\
-1.39 \text { to }-1.62\end{array}$ & $\begin{array}{l}41 \\
22 \\
11\end{array}$ \\
\hline
\end{tabular}

The relationship of the peripheral parameters to those of the lumbar spine, femoral neck, and total hip was investigated by site-matched correlation using single and multiple linear regression and ROC analysis. The correlations were significant, but only moderate, varying from 0.52 to 0.67 . This level of correlation has been observed by others and considered inadequate as a surrogate for direct-site DXA measurements of the lumbar spine and proximal femur $[1,4,5,7,9,10,11,12,14]$. Nevertheless, there may be a potential for peripheral measurement to function as a screening mechanism for central DXA if efficacious cut-points can be found. Of the four peripheral sites, the distal forearm had higher correlations than the proximal forearm, finger, and calcaneal stiffness.

ROC analysis was performed as another method of comparing the relative performance of the peripheral measurements. The AUCs for osteoporosis; and osteopenia, osteoporosis, or both, of the central regions yielded values that were moderately good, with significant differences between some of the parameters (Tables 2 and 3 ). As reported by others, optimal cut-points differed for each peripheral site $[11,14]$. Overall, the distal forearm was found to be slightly more efficacious than the other peripheral sites. No appreciable gain was derived from the combined distal and proximal forearm index compared to the distal forearm alone. To be noted is a false positive frequency that varies from $20 \%$ to $29 \%$, and a false negative frequency from $20 \%$ to $24 \%$, between the peripheral sites in the osteoporosis category in our database (Table 4). If patients with t-scores equal to or less than the optimum cut-points were given a supplemental DXA study of the lumbar spine and proximal femur for more accurate classification, the sensitivity would remain unchanged, the false positives would be eliminated, but the false negatives - i.e., patients who might be considered candidates for treatment - will remain undetected. This will also entail the cost of reexamining 41-46\% of the patients screened for osteoporosis. For osteopenia, osteoporosis, or both ( $\mathrm{t}$-score $<-1), 58-72 \%$ of patients would have the additional DXA examination (Table 5).

An alternative approach would be to determine how many false negative and false positive cases can be tolerated in a screening procedure and then develop cutpoints to satisfy the chosen limits. This would enable pa- 


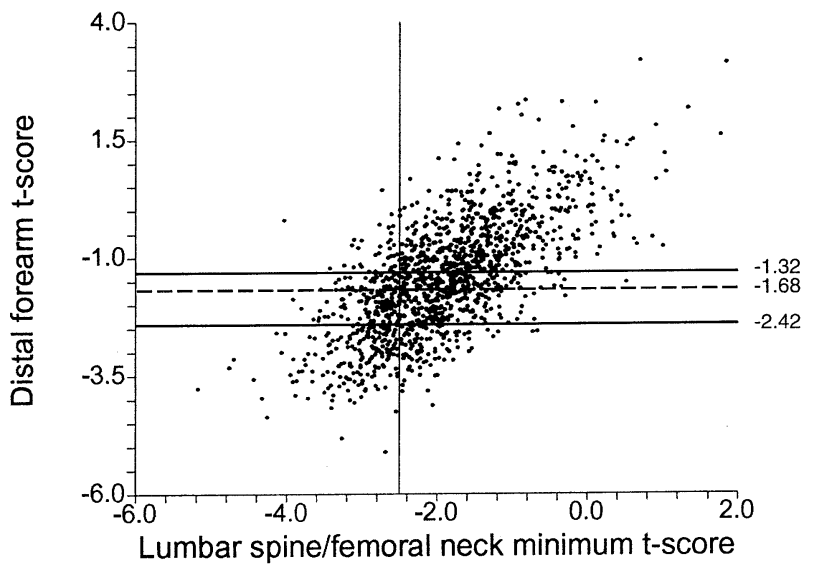

Fig. 1 Scatter plot of the distal forearm t-scores versus the minimum lumbar spine or femoral neck t-scores. Vertical line represents the boundary between osteoporosis (t-score $\leq-2.5)$ and nonosteoporosis. Solid horizontal lines are the cut-points for the $10 \%$ false negative and $10 \%$ false positive t-scores. Thirty-four percent of patients lie between these lines and require supplemental central DXA for identification. The optimum cut-point is shown by the dashed line, below which are $43 \%$ of the patients who require central DXA to identify the false positives; the false negatives remain unknown

tients above the false negative cut-point to be labeled as normal, those below the false positive cut-point to be considered for treatment without central DXA supplementation, and patients with t-scores between the cutpoints offered central DXA measurement. From our database, the percent of supplemental central DXAs incurred by the dual cut-points is shown in Tables 6 and 7 for paired 5,10 , and $15 \%$ false negatives and false positives, respectively, but any combination of percent tolerance can be calculated, such as $5 \%$ false negative and $15 \%$ false positive. Fig. 1 demonstrates graphically the difference between the dual cut-points and optimum cutpoint. The proportion of the screened population requiring DXA varies with the cut-point interval, and this ranges from $20 \%$ to $67 \%$ for the intervals chosen in Table 6 for osteoporosis. Of the four peripheral sites, the referral rates for the distal forearm was generally lower than those of the calcaneal stiffness and finger by a few percentage points. No improvement was derived from the combined forearm index over the distal forearm alone for osteoporosis, but there was a small benefit for osteopenia, osteoporosis, or both category (Table 7).

The proportion of patients requiring supplemental central DXA is the same or less for the preselected twin cut-points of $10 \%$ false negative and $10 \%$ false positive than for the optimal cut-point of the various sites (compare Tables 4 and 6). Greater differences are registered at all paired cut-points between the two methods for the osteopenia, osteoporosis, or both, category (compare Tables 5 and 7). At the distal forearm, for example, using the optimum cut-point of -1.68 for osteoporosis, $43 \%$ of the patients will require DXA supplementation. This will result in an unchanged sensitivity of $80 \%$ (20\% false negative), and an increase in specificity from $71 \%$ (29\% false positive) to $100 \%$ specificity ( $0 \%$ false positive). In contrast, by utilizing $10 \%$ false negative and false positive cut-points, $34 \%$ will have supplemental DXA and the sensitivity and specificity will be constrained to a value of $90 \%$.

A contentious issue is the proportion of patients referred for central DXA; what number would be considered economically and logistically efficacious? This depends on various factors, including the cost of the examination and, in outlying regions, the expense incurred traveling to a distant DXA facility. The number of false negatives and false positives that can be tolerated is a subjective choice, but it is inversely related to the number of patients requiring central DXA measurement for classification. If a viable compromise between the two cannot be reached, then none of the peripheral sites investigated can qualify for DXA screening.

Needless to say, a thorough clinical assessment for fracture risk may alter the algorithm in individual cases. It has been established that the best predictor of hip fracture risk, which is a major consideration, is direct-site measurement, and this has been reinforced by mechanical failure testing of the lumbar spine, proximal femur, and distal radius $[2,15]$.

\section{References}

1. Boxsein ML, Parker RA, Greenspan SL (1999) Forearm bone densitometry cannot be used to monitor response to alendronate therapy in postmenopausal women. Osteoporosis Int 10: 505-509

2. Eckstein F, Lochmuller E, Lill CH, Kuhn V, Schneider E, et al (2002) Bone strength at clinically relevant sites display substantial heterogeneity and is best predicted from site-specific bone densitometry. J Bone Miner Res 17:162-171

3. Genant HK, Grampp S, Gluer, CC, Faulkner KG, Jergas M, Engelke K, et al (1994) Universal standardization for dual xray absorptiometry: patient and phantom cross-calibration results. J Bone Miner Res 9:1503-1514

4. Grampp S, Genant HK, Mathur A, Lang P, Jergas M, et al (1997) Comparisons of noninvasive bone mineral measurements in assessing age-related loss, fracture discrimination and diagnostic classification. J Bone Miner Res 12:679711

5. Grampp S, Henk C, Lu Y, Krestan C, Resch H, Kainberger F, et al (2000) Quantitative US of the calcaneus: cutoff levels for the distinction of health and osteoporotic individuals. Radiology 220:400-405

6. Kanis JC, Melton L, Christiansen C, Johnson CC, Khaltaev N (1994) Perspective: The diagnosis of osteoporosis. J Bone Miner Res 9:1137-1141

7. Langton CM, Langton DK (2000) Comparison of bone mineral density and quantitative ultrasound of the calcaneus: sitematched correlation and discrimination of axial status. $\mathrm{Br}$ J Radiol 73:31-35

8. Looker A, Wahner H, Dunn W, Calvo M, Harris T, Heyse S, et al (1998) Update on proximal femur bone mineral levels of US adults. Osteoporosis Int 8:468-489

9. Mulder JE, Michaeli D, Flaster ER, Siris E (2000) Comparison of bone mineral density of the phalanges, lumbar spine, hip and forearm for the assessment of osteoporosis in postmenopausal women. J Clin Densitom 3:373-381

10. Njeh CF, Boivin CM, Langton CM (1997) The role of ultrasound in the assessment of osteoporosis: a review. Osteoporosis Int 7:7-22 
11. Pouilles JM, Tremollieres FA, Martinez S, Delsol M, Ribot C (2001) Ability of peripheral DXA measurements of the forearm to predict low axial bone mineral density at menopause. Osteoporosis Int 12:71-76

12. Rosenthall L, Tenenhouse A, Caminis JN (1995) A correlative study of ultrasound calcaneal and dual-energy x-ray absorptiometry bone measurement of the lumbar spine and femur in 1000 women. Eur J Nucl Med 22:402-406

13. Tenenhouse A, Joseph A, Kreiger N, Poliquin S, Murray TM, Blondeau L, et al (2000) Estimation of the prevalence of low bone density in Canadian women and men using a populationspecific DXA standard: the Canadian Multicenter Osteoporosis Study. Osteoporosis Int 11:897-904
14. Varney LF, Parker RA, Vicelette A, Greenspan SP (1999) Classification of osteoporosis and osteopenia in postmenopausal women is dependent on site-specific analysis. J Clin Densitom 2:275-283

15. Woodhouse A, Black DM (2000) BMD at various sites for prediction of hip fracture: a meta-analysis of women [abstract]. J Bone Miner Res 15 [Suppl 1]:S145

16. WHO technical report series 843. Assessment of fracture risk and its application to screen for postmenopausal osteoporosis (1994) World Health Organization, Geneva 